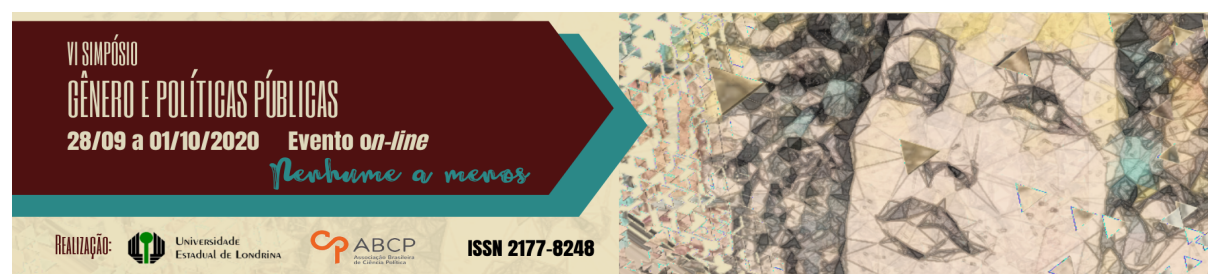

\title{
O acolhimento na área obstétrica como prática e política pública no serviço público de saúde
}

\author{
Gloria Maria Pereira Funes ${ }^{1}$; Cíntia de Souza Batista Tortato ${ }^{2}$
}

\begin{abstract}
Resumo
O objetivo desse trabalho é investigar os aspectos que envolvem o acolhimento na área obstetrícia e averiguar a sua aplicabilidade como prática e política pública no serviço público de saúde. A partir de uma revisão bibliográfica e documental, verifica-se que a percepção do acolhimento tem se definido de forma restrita em uma recepção burocrática e triagem médica que não avalia adequadamente a gravidade do problema de saúde e o grau de sofrimento do(a) paciente. É evidente a relação de poder e hierarquia entre os(a) profissionais da saúde e os(a) pacientes, principalmente no âmbito da obstetrícia, marcada por intensa intervenção profissional e medicalização do parto. $\mathrm{O}$ acolhimento é uma tecnologia leve que possibilita aproximar e fortalecer o vínculo entre profissional de saúde e usuário, pois pode gerar sensibilidade para escutar e dialogar, promovendo uma relação ética, solidária e colaborativa entre os envolvidos. Nesse sentido, a bioética e o biodireito possuem como prisma a dignidade da pessoa humana, os quais propõem reflexões éticas e jurídicas. Assim, aliados aos recursos tecnológicos (acolhimento, vínculo, acesso, entre outros), possam gerar maior flexibilidade e horizontalidade na interação social e nas ações de saúde mais ágeis, acolhedoras e decisivas.
\end{abstract}

Palavras-chave: acolhimento; obstetrícia; política pública; biodireito; bioética.

\footnotetext{
${ }_{1}^{1}$ Mestranda no Programa de Pós-Graduação em Ciência, Tecnologia e Sociedade pelo Instituto Federal do Paraná - Campus Paranaguá/PR. Membro da Comissão da Advocacia Iniciante da Subseção de Paranaguá/PR. Advogada. E-mail: gloriafunesdireito@gmail.com

2 Doutora em Tecnologia e Sociedade pela Universidade Tecnológica Federal do Paraná. Docente do Programa de Pós-Graduação em Ciência, Tecnologia e Sociedade do Instituto Federal do Paraná - Campus Paranaguá/PR.

E-mail: cintia.tortato@ifpr.edu.br
}

GT 06 - Gênero, cuidado e políticas de saúde 


\title{
Reception in the obstetric area as a public policy and practice in the public health service
}

\begin{abstract}
The objective of this work is to investigate the aspects that involve reception in the obstetric area and to investigate its applicability as a public policy and practice in the public health service. Based on a bibliographic and documentary review, it appears that the perception of hospitality has been defined in a restricted way in a bureaucratic reception and medical screening that does not adequately assess the severity of the health problem and the degree of suffering of the patient. The relationship of power and hierarchy between health professionals and patients is evident, mainly in the scope of obstetrics, marked by intense professional intervention and medicalization of childbirth. User embracement is a light technology that makes it possible to approach and strengthen the bond between health professionals and users, as it can generate sensitivity to listen and dialogue, promoting an ethical, solidary and collaborative relationship between those involved. In this sense, bioethics and bio-law have as a prism the dignity of the human person, which propose ethical and legal reflections. Thus, together with technological resources (accommodation, bonding, access, among others), they can generate greater flexibility and horizontality in social interaction and in more agile, welcoming and decisive health actions.
\end{abstract}

Keywords: reception; obstetrics; public policy; bi-right; bioethics.

\section{Introdução}

O acolhimento é um termo muito utilizado para demonstrar as relações entre profissionais e pacientes, não sendo apenas uma relação de prestação de serviços. Se caracteriza o acolhimento como tecnologia leve, importante para reorganizar os processos gerenciais e gerar vínculo entre profissionais e usuários, a fim de proporcionar a ampliação do acesso à saúde, uma resolução do atendimento e adequar o serviço de acordo com as necessidades dos usuários (GUERRO, MELO; ANDRADE; ERDMAN, 2013).

$\mathrm{O}$ acolhimento como um recurso tecnológico pode promover a subjetividade dos sujeitos e a dignidade humana, em virtude da possibilidade de expandir as ações de saúde para um trabalho com interação 
social, maior inserção e criatividade da equipe (ALMEIDA; MISHIMA, 2001 apud COELHO; JORGE, 2009, p. 1524).

No Brasil, o Ministério da Sáude desenvolveu o Programa de Humanização do Pré-natal e Nascimento (PHPN), cuja política pública possui o objetivo de proporcionar o acesso e a qualidade do cuidado no ciclo gravídico-puerperal (MINISTÉRIO DA SAÚDE, 2006). Pois, a visão do acolhimento realizado pelos profissionais se reduz a uma prática de recepção e triagem da demanda sem avaliar adequadamente a gravidade do problema de saúde, gerando uma percepção nas gestantes, parturientes e puérperas, de que as necessidades do ciclo gravídico-puerperal, são desconsideradas (CORREA; FELICIANO; PEDROSA; SOUZA, 2017, p.2).

Ao exercer o acolhimento como tecnologia leve, a bioética e o biodireito podem ser ferramentas importantes na promoção do cuidado, pois são intermediadores de conflitos pautados no princípio da dignidade da pessoa humana. A partir de discussões e reflexões nesses dois campos, é possível criar posturas críticas, capazes de combater posicionamentos médicos absolutos, dogmáticos e hierarquizados.

Nesse contexto, em um primeiro momento se busca abordar o acolhimento como tecnologia leve. Em seguida, se objetiva analisar a bioética e o biodireito como dispositivos aliados ao acolhimento. E por fim, investigar os aspectos que envolvem o acolhimento na área obstetrícia e averiguar a sua aplicabilidade como prática e política pública no serviço público de saúde.

Se descata que o presente artigo é resultado preliminar da coleta e construção da revisão de literatura da dissertação de mestrado acadêmico da primeira autora no Programa de Pós-Graduação em Ciência, Tecnologia e Sociedade do Instituto Federal do Paraná - Campus Paranaguá. Dessa forma, a pesquisa sobre o acolhimento frente a violência obstétrica se encontra em fase de desenvolvimento. 


\section{Acolhimento como tecnologia leve}

O tempo e o espaço são considerados importantes para a vida social em diversas situações, em virtude das distintas qualidades materiais objetivas e das apreciações subjetivas que podem ocasionar os conflitos de ordem teórica, prática, científica, social e estética (HARVEY, 2002, p. 190). Logo, as práticas e reproduções comuns são estabelecidas por meio da relação dialética, formada entre o corpo e um organismo estruturado do espaço e tempo (BORDIEU, 1977 apud HARVEY, 2002, p. 198).

Quando se investiga as ideologizações da tecnologia, é necessário arguir a exaltação do presente. As sociedades fragmentadas possuem características dominantes que exaltam o presente, no qual se estejam devidamente inseridos e se beneficiem das ferramentas existentes. As circunstâncias sociais, técnicas e científicas são ascendidos por essas características dominantes (VIEIRA PINTO, 2005, p. 39).

A construção de tempo e espaço na identidade cultural de gênero, produz esteriótipos de papéis diferenciados, definidos conforme os interesses imediatos de cada sociedade e em cada momento histórico. Ao longo dos anos, na área médica, o modelo social patriarcalista prédefiniu modos de conhecimento e ação, com o intuito de perpetuar as relações de poder entre os sexos (BRASIL, 2001, p. 12).

Assim, é preciso cuidado frente ao endeusamento tecnológico, tendo em vista que o objetivo é fortificar os interesses dos autores do saber atual, que culminam na exclusão social e espoliação econômica (VIEIRA PINTO, 2005, p. 44). Por serem criações humanas, com a função de servir ao interesse das pessoas, tanto a técnica como a tecnologia não podem ser vistas como boas ou más, mas sim depende da forma de utilização que se fazem delas (VIEIRA PINTO, 2005, p. 347)

Por isso, abordar o acolhimento como tecnologia leve é importante para que haja a mudança de conscientização frente a paradigmas criados por esse modelo social, em especial na área obstétrica, que não protege a mulher das vulnerabilidades do ciclo gravídio-puerperal. 
O acolhimento é uma palavra que remete o conceito de consideração, atenção, atender ou abrigar. Na área da saúde, o exercício do acolhimento "deve possuir como critérios simultâneos a ética/estética/política para produzir saúde e ferramenta tecnológica de intervenção na qualificação de escuta, construção de vínculo, garantia do acesso com responsabilização e resolutividade nos serviços" (BRASIL, Cartilha da PNH, 2010, p. 18).

Alinhado com o acolhimento, a humanização é um dispositivo associado, caracterizado como uma "estratégia de intervenção no processo de produção da saúde", a partir da "construção e realização de condutas de caráter ético/estético/políticas, em sincronia com um programa de corrresponsabilidade e qualificação de vínculos interprofissionais e entre estes e os usuários" (BRASIL, 2004a, p. 8).

Se observa que os critérios são concomitantes, em virtude da ética atribuir "ao compromisso de identificar o outro, na conduta de acolher em suas diferenças, dores, modos de viver e sentir a vida". A estética se fundamentar "na invenção de estratégias que colaboram para tornar a vida e o viver dignos, para criar a nossa própria humanidade". E a dimensão política por "provocar o compromisso coletivo de estar ao lado, intensificando protagonismos e vida nas diversas relações" (BRASIL, Cartilha da PHN, 2010, p.6).

Os princípios da humanização de cuidado direcionam as ações de saúde através de tecnologias e composições, que configuram e fortalecem as áreas entre a saúde e a comunidade (COELHO;. JORGE, 2009, p. 1524).

Para a promoção e práticas da saúde, a Política Nacional de Humanização (PHN) do Sistema Único de Sáude (SUS) determina o acolhimento como um dos processos constitutivos na Atenção Básica (AB) e nos demais níveis do sistema. Através dessa tecnologia leve se desenvolve o diálogo, a postura e a reorganização dos serviços, formando as dimensões do acolhimento (TEIXEIRA, 2005, p. 89-111). 
Isso significa que a produção de cuidado ultrapassa a área do conhecimento técnico e do manejar de ferramentas, pois é direcionado ao trabalho humanizado por intermédio de tecnologias leves. Por isso, as tecnologias leves também são chamadas de relacionais, porque pertencem a área da interpessoalidade e geram as relações de interações e subjetividade entre os sujeitos (MEHRY, 2002 apud FERRI, 2007, p. 518).

Por conseguinte, o acolhimento pode ser considerado como um caminho para efetivar a humanização das práticas de saúde, que vai além da escuta e da fala, mas sim um conjunto de providências, ações e posturas dos(as) profissionais da saúde para garantir confiabilidade e importância, gerando respeito e solidariedade entre estes e os(as) pacientes (BRASIL, 2010, p. 264).

A partir da relação firmada entre os(as) profissionais de saúde e os(as) usuários, através de ações que constituem iniciativas humanizadoras - apresentar-se, chamar os(as) usuários pelo nome, prestar informações sobre condutas e procedimentos que devam ser realizados, reforçar o acompanhamento por uma pessoa de confiança do(as) paciente, por exemplo - o acolhimento é caracterizado como um recurso transversal que engloba as práticas de saúde (BRASIL, 2013, p. 40).

Se observa que o acolhimento busca incluir todos os tipos de usuários, não somente aqueles de determinados grupos, como os portadores de agravos mais preponderantes e/ou recortados conforme os ciclos de vida, "são objeto privilegiado do trabalho das equipes, bem como as pessoas que demonstram necessidades de saúde e que não encaixam nos nesses" (BRASIL, 2011, p. 21-2).

A partir disso, as tecnologias podem se classificar como leve, leve-dura e dura, as quais tratam a tecnologia de modo amplo, através da análise total do processo produtivo até o produto final. $\mathrm{O}$ acolhimento se caracteriza como tecnologia leve das relações, importante geradora de vínculos, se torna necessária ao mecanismo tecnológico para o funcionamento do trabalho (COELHO; JORGE, 2009, p. 1524). 
Portanto, as tecnologias leves buscam a substituição a tradicional relação distanciada, supostamente neutra e livre de afetos, por "níveis mais profundos de acolhimento e vínculo" com os(a) pacientes e suas famílias (CERON, 2010, p. 26). Assim, os(a) profissionais da saúde podem se tornar participantes da saúde dos(as) usuários, promovendo a responsabilidade destes por sua vida e a construção de sua saúde (COELHO; JORGE, 2009, p. 1527).

É necessário tal substituição da relação queixa-conduta pautada em um atendimento de ações de saúde automáticas e desumanizadas, cujo impacto nas interações entre profissional de saúde e paciente se reduz a mero valor mercantil de troca.

Por isso, o comprometimento com o sujeito pode proporcionar aos profissionais de saúde não unicamente as percepções da doença, mas também permite se sensibilizar e comprender as circunstâncias sociais, pessoais, culturais, econômicas e políticas que os(as) pacientes vivem.

\section{A bioética e o biodireito como dispositivos essenciais ao acolhimento na área obstétrica}

A desvalorização das situações cotidianas que ocorre nas unidades de saúde, não permite a abrangência total da bioética, pois a atenção à saúde se mantem centralizada somente na doença, perfazendo um agrupamento homogêneo de serviços e de ações (BRODY, 1989 apud SILVA; ZOBOLI; BORGES, 2006, p. 134).

O problema ético do desrespeito nas relações entre profissionais de saúde e pacientes, pode trazer resultados imprevisíveis na produção e na manutenção da saúde, pois ocasiona um conflito de interesses. $\mathrm{O}(\mathrm{a})$ paciente almeja uma solução para o seu problema de saúde e o(a) profissional, por diversas vezes, se prende a normas, procedimentos e rotinas do serviço e/ ou a sua percepção técnica da melhor solução em face da doença do(a) usuário (SILVA; ZOBOLI; BORGES, 2006, p. 136). 
Porém, antes mesmo de ser uma regulamentação de valores, princípios, regras ou técnicas, a ética denomina "a reflexão sobre o conjunto das exigências do respeito e da promoção da pessoa" (voluntariedade) (DURAND, 1999, p. 83). A ética empreende a livre adesão, de modo que é um ideal a ser alcançado.

Nesse sentido, a bioética é considerada como parte da ética, sendo uma ética aplicada em razão da aproximação a um objeto de estudo comum. Com base nas ciências sociais objetiva consolidar um conjunto de valores para resolver problemas éticos oriundos das descobertas e intervenções biotecnológicas (CASABONA, 2005 apud RIVABEM, 2017, p. 284).

De modo a solucionar os conflitos bioéticos, compete ao biodireito dar soluções jurídicas, com o objetivo de proteger o ser humano em sua totalidade, baseado na sistematização de princípios e valores caracterizados como interligados e universais (RIVABEM, 2017, p. 284).

Embora a bioética e o biodireito possuam reflexões e atuações em campos diferentes, ambos detêm como norte a dignidade da pessoa humana. Para a biótica é relevante averiguar que "os corpos submetidos a uma medicalização já se encontrem juridicizados e vice-versa". A interpretação do corpo como entidade cultural é conferido pela medicalização e a juridicização, estes que são processos fundamentais que mantêm a ética sob o seu poder (BROEKMAN, 1998, p. 15 apud RIVABEM, 2017, p. 284).

No entanto, o direito pode ser estudado do ponto de vista dogmático, como protocolo para solucionar conflitos, enquanto a ética pode fornecer subsídios para definição e aplicação do direito, com atuação de ordem normativa acessória no mundo jurídico (SÁ, 2015, p. 9 apud RIVABEM, 2017, p. 285). Dessa forma, os valores éticos podem refletir através das normas jurídicas, a fim de resgatar a dimensão valorativa do direito. 
Na área obstétrica, o corpo e os sintomas da mulher são controlados pelos(as) profissionais de saúde durante o ciclo gravídico-puerperal, que desconsidera particularidades, subjetividades e a participação da paciente. A intensa medicalização do corpo feminino pode impedir as mulheres de serem protagonistas durante o período pré/pós-natal, parto e pós-parto, ocasionando desassistência e sofrimentos diversos (CURI; BAPTISTA, 2017, p. 129-131).

As ordens dadas pelos(as) profissionais de saúde podem extinguir a autonomia, o protagonismo e a dignidade da mulher. Inclusive, a manifestação da paciente quanto aos procedimentos que será submetida, a queixa das dores do parto ou a morosa espera por atendimento na unidade hospitalar, podem ser ignoradas pelos(as) profissionais. Tal qual ocasiona uma assistência ao parto que conduz a mulher em uma situação de submissão e vulnerabilidade diante do poder médico (ANDREZZO, 2016, p. 72).

A violência obstétrica que ocorre nessas condições em face das pacientes, pode ser banida pela aplicabilidade da bioética e do biodireito, que possuem a dignidade da pessoa humana como aparato de sustentação na interação do(a) profissional de saúde com a mulher, seus familiares e o recém-nascido, pois podem realizar condutas com conteúdo procedimental de caráter humanista no processo de acolhimento.

Além disso, a bioética e o biodireito podem fortalecer a humanização durante o acolhimento, de modo a cessar rotinas técnicas que determinam um isolamento à mulher. Ainda, se pode adotar medidas mais benéficas durante o pré/pós-natal, trabalho de parto e parto, a fim de se afastar ações desnecessárias que venham a ocasionar riscos à mulher e ao recém-nascido (RODRIGUES, 2017, p. 25).

Enquanto estratégia para reestruturar o processo de trabalho das equipes de saúde e focar a atenção à saúde no(a) usuário, o acolhimento requer a utilização de ferramentas e formas de administração e gestão que priorizem as pessoas, ou seja, pautados em valores que reconheçam as pessoas como prioridade (ZOBOLI; FRACOLLI, 2006, p. 313). 
A partir da direção dos valores, estes são compartilhados entre profissionais e usuários em dois grupos, quais sejam, os finais e os instrumentais. Os valores finais que se caracterizam por estar relacionado à visão e à missão organizacionais. E o grupo de valores instrumentais ou operativos, são as formas de pensar e agir, com base na organização de afrontar as demandas e compor as suas tensões internas, com o intuito de alcançar sua visão e sua missão (GARCIA; SHIMON, 1996 apud ZOBOLI; FRACOLLI, 2006, p. 315).

Por conseguinte, a introdução de determinados valores como a confiança, a justiça e o respeito à pessoa, podem fortalecer a dedicação das equipes quanto ao acolhimento, gerando mais entusiasmo e desempenho profissionais. Quando extensamente aceitos pelas pacientes, a comunicação é melhor e mais precisa, ampliando a integridade no processo de tomada de decisão e o aumento a capacidade administrativa de examinar os projetos e os trabalhadores da saúde (CHIAVENATO, 1994; BADARACCO; ELLSWORTH, 1996 apud ZOBOLI; FRACOLLI, 2006, p. 316).

Portanto, a dignidade é um valor intrínseco ao ser humano, tendo em vista que está atrelada à moral e à boa conduta, portanto, inserida no decurso das ordens jurídicas e políticas (BARROSO, 2013 apud RODRIGUES, 2017, p. 27). A autonomia e a dignidade são violadas, quando o(a) profissional de saúde executa um procedimento sem o consentimento da paciente. O consentimento é o resultado de uma interação bem sucedida, em razão de aceitar o posicionamento conforme as crenças, os valores e a cultura que envolvem o(a) paciente (ENGELHARDT JR, 2011).

\section{A aplicabilidade do acolhimento como prática e política pública no serviço público de saúde}

Muitas vezes a interação profissional-usuário se reduz a execução acrítica do conhecimento técnico-científico, pois o(a) profissional 
deve ter atenção e cautela voltados para relação entre melhorar a atuação do saber técnico, de forma a respeitar as subjetividades, e agir em face das necessidades e ações de saúde (GADEMER, 2006 apud CORREAA; FELICIANO; PEDROSA; SOUZA, 2017, p. 9).

As pessoas repetem suas ações e atribuíem a estas um sentido que é entendido por certo conforme a cada repetição em virtude da indeterminação da estrutura instintiva, as pessoas acabam por sentir um "alívio psicológico". As instituições necessitam da legitimidade das gerações sucessoras, a fim de que suas concepções sejam incorporadas no dia a dia por meio dos crenças, mitos, tabus, entre outros, que compõem o processo de socialização (BERGER; LUCKMANN, 2004).

A intensa internalização dessas concepções que as instituições exercem como se estivessem sob as pessoas, formam uma ordem social socialmente criada que pode ser vivenciada por uma ordem predeterminada e entendida como correta. Desse modo, a ordem predeterminada se transforma em real e não pode ser mais modificada de modo imediato. Logo, a prática social é uma atividade humana, que gera a realidade social (BERGER; LUCKMANN, 2004).

Portanto, a reflexão e a alteração dos modos de exercer a assistência através do acolhimento como dispositivo técnico-assistencial, pode questionar as relações clínicas de acesso aos serviços, de trabalho da saúde e das formas de atenção e gestão. A avaliação de vulnerabilidade e risco também precisa ser o foco de atenção do profissional da saúde, levando em consideração o grau de sofrimento físico e psíquico da paciente (BRASIL, 2010, p. 25).

Por sua vez, ao mesmo tempo que as pessoas produzem a ordem social, também são modificados por esta, tendo em vista que a ordem social interpreta a elaboração do mundo social como das interações intersubjetivas de vários níveis. Mesmo que de maneira objetiva a realidade da vida se manifeste, é também uma vivência intersubjetiva (BERGER; LUCKMANN, 2004). 
Como descrito, o acolhimento é uma tecnologia que visa a transformação das práticas de atenção e gestão da saúde. À vista disso, por exemplo, o Acolhimento com Classificação de Risco é uma tecnologia com o objetivo de proporcionar o atendimento nas urgências e emergências de forma a diminuir o tempo de espera, para que seja possível aliviar a dor e sofrimento da paciente e de seus familiares (BRASIL, 2010).

O acolhimento recebe lugar de destaque do Sistema Único de Saúde (SUS), tendo em vista que possui o objetivo de superar o domínio do modelo biomédico com foco na doença, no tecnicismo e da hierarquia de saber técnico e científico entre profissional de saúde e usuário (BOSI; MERCADO, 2006).

Dessa maneira, para buscar o bem estar social, as políticas públicas são planos, metas e ações manuseadas pelos governos, as quais advêm os requerimentos pelas pessoas que integram a sociedade, sendo efeito de uma apuração realizada pelo poder público das várias necessidades apontadas por estas pessoas (RUA, 2009 apud MARQUES, 2012, p. 13).

No campo do SUS (Sistema Único de Saúde), o Programa de Humanização no Pré-Natal e Nascimento (Portaria/GM n ${ }^{\circ} 569$, de 1/6/2000), integra a Política Nacional de Humanização, chamada de HumanizaSUS (criada em 2003), como objetivo de efetuar os princípios do SUS no dia a dia das práticas de gestão e de atenção, incentivando o diálogo entre profissionais, gestores e usuários do SUS. Portanto, se busca o desenvolvimento de processos coletivos que combatam relações de poder, afeto e trabalho (MINISTÉRIO DA SAÚDE, 2017).

Incorporado às concepções que conduzem os trabalhos da Política Nacional de Humanização, se encontra o acolhimento, que a partir da escuta e diálogo especializado realizado pelos agentes de saúde frente às necessidades dos(as) usuários, seja possível assegurar a acessibilidade destes a tecnologias apropriadas às suas necessidades e estender a eficácia das práticas de saúde (MINISTÉRIO DA SAÚDE, 2017). 
Em contato com a gestante, parturiente ou puérpera, a equipe de saúde precisa buscar a compreensão em face dos diversos sentidos da gestação para aquela paciente e a sua família. O acolhimento exercido durante o ciclo gravídico é uma prática fundamental não somente na criação de vínculo entre profissional e paciente, mas também de desenvolvimento da relação da mulher e a sua família estabalecerão com o bebê (BRASIL, 2005).

É importante repensar o acolhimento como política pública de modo a ultrapassar o reducionismo biológico, para que seja possível compreender as necessidades de saúde para além do corpo físico, a fim de obter respostas adequadas de modo integral e integrada, bem como reforçar as ações de prevenção (CAMELO; ANGERAMI; SILVA, 2000).

A aplicabilidade do acolhimento como prática e política pública pode ser fundamental para garantir e efetivar a humanização e diminuir as consequências negativas da hospitalização do parto. Além disso, o acolhimento busca reaproximar a mulher e seus familiares do processo gravídico-puerperal, de forma a romper tal evento como exclusivamente médico e insticucionalizado.

Por fim, são realizadas estratégias que incorporam a humanização do parto por intermédio de políticas públicas, com o intuito de transformar paradigmas do modelo tecnocrático do parto moderno. Portanto, o acolhimento é uma prática importante para realizar a mudança de atendimento na saúde pública e tornar o ambiente digno para todos os atores envolvidos.

\section{Considerações finais}

A fim de ultrapassar o modelo tecnocrático moderno do parto, pautado na forte medicalização e instucionalização, o acolhimento pode ser uma prática que possibilita a aplicabilidade de uma assistência humanizadora, que chama para o diálogo e a escuta através da interação entre profissional da saúde, usuários(a) e seus familiares. 
A bioética e o biodireito como dispositivos essenciais aliados ao acolhimento, oferecem mudanças de pensamento sob o prisma de questões éticas e jurídicas, que promovem a ampliação de reflexão do profissional de saúde em aproximar a mulher e a sua família no processo gravídico-puerperal, ou seja, visa o protagonismo desses sujeitos no respectivo processo.

Ainda, a dignidade da pessoa humana é a essência da bioética e do biodireito, que através do acolhimento podem intensificar a assistência ao parto de forma saudável para a mulher e o bebê, bem como proporcionar a troca de saberes entre o profissional de saúde e a mulher, ao passo que possibilita a formação de vínculos de nível horizontal.

O acolhimento como tecnologia leve pode ser exercido como recurso tecnológico incorporado na humanização do parto, é capaz de realizar mudanças de pensamento na ordem social, cujo o modelo tecnocrático moderno do parto entende que o somente e unicamente o profissional de saúde detêm os conhecimentos técnicos para tomar decisões pela mulher, durante o pré-natal, trabalho de parto, parto e pós-parto.

Ainda, atendimentos meramente técnicos que não investigam o grau de perigo de vida que a paciente se encontra, devem ser abandonados e substituídos pelo diálogo e a escuta qualificada, para que o acolhimento não seja unicamente um ato repressivo, mas também preventivo, a fim de evitar maiores complicações com a mulher e o bebê. Logo, a confiança, a compreensão, a paciência, a atenção, entre outros, são valores incorporados no acolhimento para gerar interações e vínculos entre os(a) profissionais de saúde, a mulher e sua parentes, para efetivamente obter resultados menos intervencionistas possíveis.

Por fim, o acolhimento como prática e política pública busca garantir e promover o acesso a saúde pública, além de possibilitar a reflexão da assistência ao parto, visando a promoção da saúde para a mulher e o bebê, como sujeitos de direito e não como objetos do processo do nascer. 


\section{Referências}

ALMEIDA M. C. P; MISHIMA, S. M. O desafio do trabalho em equipe na atenção à saúde da família: construin-do "novas autonomias" no trabalho. Interface, Botucatu, v. 5, n. 9, p. 150-153, 2001.

ANDREZZO, H. F. A. O desafio do direito à autonomia: uma experiência de Plano de Parto no SUS. 2016, 111p. Dissertação (Mestrado em Ciências). Universidade de São Paulo, São Paulo, 2016.

Área Técnica de Saúde da Mulher, Departamento de Ações Programáticas Estratégicas, Secretaria de Atenção à Saúde, Ministério da Saúde. Pré-natal e puerpério: atenção qualificada e humanizada - manual técnico. 3a Ed. Brasília: Ministério da Saúde; 2006.

BERGER P.; LUCKMANN T. A construção social da realidade: tratado de sociologia do conhecimento. Rio de Janeiro: Editora Vozes, 2004.

BOSI, M. L. M.; MERCADO, F. J. (Org.). Avaliação qualitativa de programas de saúde: enfoques emergentes. Petrópolis: Vozes, 2006.

BRASIL, Ministério da Saúde. Política Nacional da Humanização. 2004a. Disponível em: http://bvsms.saude.gov.br/bvs/publicacoes/politica_nacional_humanizacao_pnh_folheto.pdf. Acesso em: 21 jan. 2020 .

BRASIL. Departamento de Atenção Básica, Secretaria de Atenção à Saúde, Ministério da Saúde. Manual técnico pré-natal e puérpero. Política Nacional de Atenção Básica. Brasília: Ministério da Saúde; 2012.

BRASIL. Ministério da Saúde. Acolhimento nas Práticas de Produção da Saúde. $\quad 2^{\mathrm{a}}$ edição, 2010, p. 18 . Disponível em: http:/ / bvsms.saude.gov.br/bvs/publicacoes/acolhimento_praticas_producao_saude.pdf. Acesso em: 21 jan. 2020.

BRASIL. Ministério da Saúde. Programa de Humanização no Pré-natal e Nascimento. Brasília: 2000. Disponível em: https://central3.to.gov.br/arquivo/494560/. Acesso em: 01 fev. 2020.

BRASIL. Ministério da Saúde. Secretaria de Atenção à Saúde. Departamento de Atenção Básica. Saúde sexual e saúde reprodutiva. Brasília, DF: 
Ministério da Saúde; 2010. Disponível em: http:/ / bvsms.saude.gov.br/bvs/publicacoes/saude_sexual_saude_reprodutiva.pdf. Acesso em: 22 jan. 2020.

BRASIL. Ministério da Saúde. Secretaria de Atenção à Saúde. Departamento de Atenção Básica. Acolhimento à demanda espontânea. Brasília, DF: Ministério da Saúde; 2011. Disponível em: http://bvsms.saude.gov.br/bvs/publicacoes/acolhimento_demanda_espontanea_cab28v1.pdf. Acesso em: 21 fev. 2020.

BRASIL. Ministério da Saúde. Secretaria de Atenção à Saúde. Departamento de Atenção Básica. Atenção ao pré-natal de baixo risco. 1. ed. rev. Brasília, DF: Ministério da Saúde; 2013. Dispoível em: http:/ / bvsms.saude.gov.br/bvs/publicacoes/cadernos_atencao_basica_32_prenatal.pdf. Acesso em: 21 jan. 2020.

BRASIL. Ministério da Saúde. Secretaria de Atenção à Saúde. Ministério da Saúde. Parto, Aborto e Puerpério Assistência Humanizada à Mulher. Brasília, DF: Ministério da Saúde; 2001. Disponível em: http://bvsms.saude.gov.br/bvs/publicacoes/cd04_13.pdf. Acesso em: 01 fev. 2020.

BRASIL. Secretaria de Atenção à Saúde. Departamento de Ações Programáticas Estratégicas, Área Técnica de Saúde da Mulher. Pré-natal e puerpério: atenção humanizada - Manual Técnico. Brasília: Ministério da Saúde, 2005.

CAMELO SHH, ANGERAMI ELS, SILVA EM, et al. Acolhimento à clientela: estudo em unidades básicas de saúde no município de Ribeirão Preto. Rev. Latino-Am. Enfermagem [internet], 8(4), p. 30-37, 2000.

CERON, M. Habilidades de Comunicação: Abordagem centrada na pessoa. São Paulo: UNA-SUS, UNIFESP, 2010. Disponível em: https:/ / www.unasus.unifesp.br/biblioteca_ virtual/esf/2/unidades_conteudos/unidade24/unidade24.pdf. Acesso em: 24 jan. 2020.

COELHO, M. O.; JORGE, M. S. B. Tecnologia das relações como dispositivo do atendimento humanizado na atenção básica à saúde na perspectiva do acesso, do acolhimento e do vínculo. Ciênc. saúde coletiva, Rio de Janeiro, v. 14, supl. 1, 2009. 
CORREA MS, FELICIANO KV, PEDROSA EN, SOUZA AI. Acolhimento no cuidado à saúde da mulher no puerpério. Cad. Saúde Pública, Rio de Janeiro, v. 33, n. 3, 2017.

CURI, P. L.; BAPTISTA, J. G. B. A medicalização do corpo de mulher e a violência obstétrica. ECOS, Estudos Contemporâneos da Subjetividade. Ano 8. Volume 1. Disponível em: www.periodicoshumanas.uff.br/ecos/article/download/2092/1537. Acesso em: 26 jan. 2020.

DURAND G. Introdução geral à bioética. São Paulo: Loyola; 1999. p. 83.

ENGELHARDT JUNIOR, H. T. Fundamentos da bioética. Trad. CESCHIN, J. A. São Paulo: Edições Loyola, 2011.

FERRI, S M N; PEREIRA, M B; MISHIMA, S M; CACCIA-BAVA, M C G; ALMEIDA, M C P. As tecnologias leves como geradoras de satisfação em usuários de uma unidade de saúde da família. Interface-Comunic., Saúde, Educ., v. 11, n. 23, p. 515-29, set./ dez. 2007.

GUERREO, P.; MELLO, A. L. S. F.; ANDRADE, S. R.; ERDMAN, A. L. $\mathrm{O}$ acolhimento como boa prática na atenção básica à saúde. Emfermagem, Florianópolis, v. 22, n. 1, p. 132-40, 2013.

HARVEY, D. Condição Pós-moderna. São Paulo: Cortez, 2002.

MARQUES, A. N. Políticas Públicas de Saúde: Análise do acolhimento às gestantes do município de Guararema (SP). Monografia (Especialização em Gestão Pública Municipal). Universidade Tecnológica Federal do Paraná - Campus Curitiba. Curitiba, 2012. Disponível em: http:// reposito-

rio.roca.ufpr.edu.br/jspui/bitstream/1/1684/1/CT_GPM_II_2012_2 2.pdf. Acesso em: 02 fev. 2020.

RIVABEM, F. S. Biodireito: uma disciplina autônoma?. Rev. bioét. (Impr.), v. 25, n. 2, p. 282-289, 2017.

RODRIGUES, M. S. Humanização no processo de parto e nascimento: implicações no plano de parto. 2017. 102 f. Dissertação (Mestrado em Enfermagem) - Escola de Enfermagem da Universidade Federal de Minas Gerais, Belo Horizonte, 2017. 
SANTOS, J. A. T.; VARGENS, O. M. C. Construindo uma concepção de tecnologia de cuidado de enfermagem obstétrica: estudo sociopoético. Contexto Enferm, Florianópolis, v. 17, n. 4, p. 656-664, 2008.

SILVA D. M.; SERRA M. C. M. Violência obstétrica: uma análise sob o prismo da autonomia, beneficiência e dignidade da pessoa humana. Revista Brasileira de Direitos e Garantias Fundamentais, Maranhão, v. 3. n. 2, p. 42-65, jul./dez. 2017.

DA SILVA, L. T.; ZOBOLI, E. L. C. P.; BORGES, A. L. V. Bioética e atenção básica: um estudo exploratório dos problemas éticos vividos por enfermeiros e médicos no PSF. Cogitare Enfermagem, v. 11, n. 2, 2006.

TEIXEIRA, R. R. O acolhimento num serviço de saúde entendido como uma rede de conversações. In: PINHEIRO R.; MATTOS R. A. (Org.). Construção da integralidade: cotidiano, saberes e práticas em saúde. Rio de Janeiro (RJ): IMS/UERJ/Abrasco; 2005. p. 89-111.

VIEIRA PINTO, A. O conceito de Tecnologia. V1. Rio de Janeiro: Contraponto, 2005.

ZOBOLI, E.; FRACOLLI, L. A incorporação de valores na gestão das unidades de saúde: chave para o acolhimento. O mundo da saúde, São Paulo, v. 30, n. 2, p. 312-317, 2006. 